\title{
The Anthropocene Operating Space for Antimicrobial Resistance: tipping points in treatability of priority pathogens
}

1 Tiscar Graells ${ }^{1 *}$, Christine Heinzel ${ }^{2,3}$, Peter Søgaard Jørgensen ${ }^{1,2}$

\author{
${ }^{1}$ Global Economic Dynamics and the Biosphere, Royal Swedish Academy of Sciences, Stockholm, Sweden \\ ${ }^{2}$ Stockholm Resilience Centre, Stockholm University, Stockholm, Sweden \\ ${ }^{3}$ Department of Geography, Rheinische Friedrich-Wilhelms University Bonn, Bonn, Germany \\ * Correspondence: \\ Tiscar Graells, $\mathrm{PhD}$ \\ tiscar@kva.se; tiscar.graells@e-campus.uab.cat;
}

Keywords: antimicrobial resistance, antibiotic resistance, Anthropocene, treatability, Public health, Global Health, One Health, resilience.

\section{Word count: 7006}

Figures: 1

Tables: 6

\begin{abstract}
Evolution of antimicrobial resistance, especially antibiotic resistance, results from complex dynamics between microorganisms, stressors and the environment itself, where non-linear dynamics are present with unpredictable impacts on treatability, and therefore, on society. The Anthropocene Operating Space for Antimicrobial Resistance is a recent framework for riskassessment of tipping-points in treatability by combining information about the level of resistance and the effects of available antimicrobials. Here, we develop this framework at an increased level of resolution and extent compared to previous analysis adding three sub-zones to the original three zone framework and applying it to 20 priority pathogens, constituting its first application at the pathogen level, including fungal pathogens. In doing so, we also provide updated definitions of each zone and sub-zone together with an overview of mechanisms and contexts contributing to treatability of tipping point risks. We find that 7 out of 20 assessed priority pathogens (6 out of 11 Gram-negative bacteria) are in the zone of highest risk where widespread tipping points in treatability are most likely (surpassed zone). Namely, Acinetobacter spp., Pseudomonas spp., Enterobacteriaceae (Escherichia coli and Klebsiella pneumoniae), Neisseria gonorrhoeae and the yeast Candida auris are those assessed exceeding our current resources. Meanwhile, Mycobacterium tuberculosis, Clostridioides difficile, Staphylococcus aureus, Enterococcus and Salmonella are classified at very high risk of crossing the tipping point in treatability. The problem of antimicrobial resistance is often described as a future threat in the so-called post-antibiotic era. However, our assessment concludes we may have surpassed the threshold in some of the scenarios, and that we are on the edge in others. The proposed framework, being easy to implement across sectors, while requiring little or no economic investment, unifies criteria to be used between different key actors joining two important parameters in antimicrobial resistance: the epidemiological state of priority pathogens and treatment sustainability. In the future the framework can be expanded to other pathogens and repeated assessments will be useful as an indicator of tracking trends in treatability tipping-point risks.
\end{abstract}




\section{The Anthropocene Operating Space for antimicrobial resistance: tipping points in treatability of priority pathogens}

\section{Introduction}

The effectiveness of antibiotics has been waning since they were introduced into modern medicine over 70 years ago. Today our inability to treat infections compromises clinical practices previously taken for granted (e.g. prophylactic use in surgery, cancer or dialysis) and affects negatively patient outcomes including higher mortality and/or morbidity. Antimicrobial resistance (AMR) increases costs in the healthcare system due to (i) more extended periods in facilities, (ii) infection control interventions and (iii) need for more costly alternative therapies (Wernli et al., 2017; Kousouli et al., 2019). Although governments have recently committed to take action and mitigate the effects of AMR, the consequences for human health are likely to worsen given the global increase in antibiotic use (50\% between 2000 and 2015) (Klein et al., 2018), the projected increase in antibiotic use for livestock production (Van Boeckel et al., 2017) and the extensive and often un-reported use of antimicrobials in the growing aquaculture sector (Henriksson et al., 2018). AMR ranks alongside climate change as a global environmental challenge (Laxminarayan et al., 2016; Jørgensen et al., 2018) with antibiotic resistant infections involved in the deaths of hundreds of thousands of people every year (Laxminarayan et al., 2016; US CDC, 2019) and healthcare associated costs estimated in billions of dollars (for direct, additional costs and lost productivity) per year in the United States alone (van Duin and Doi, 2017).

Previously known susceptible strains have acquired resistance (Van Hoek et al., 2011) typically due to selection pressure of antimicrobials and their residues that select for advantageous mutations that affect strains clonally (intraspecific) within microbial populations (Aslam et al., 2018). Although this happens naturally, environments influenced by anthropogenic forces (e.g. the release of antimicrobials or their residues in natural settings) become 'hotspots' due to strong ecoevolutionary dynamics between human activity and the environment (Jørgensen et al., 2020) . 'Hotspots' are those ecosystems where emergence, spread and persistence of resistance is likely to happen. Examples are hospitals, farms, wastewater or pharmaceutical facilities (Andersson and Hughes, 2011; Gullberg et al., 2011; Kristiansson et al., 2011; Kraemer et al., 2019). Microorganisms live in complex ecosystems where they interact simultaneously with each other, with the environment and on multiple levels. This can lead to different responses to the same condition making outcomes uncertain and hindering long-term predictions. This aperiodic behaviour due to non-linear dynamics (Strogatz, 2007) in microorganisms (Table 1) can perpetuate, spread or hinder resistance (Holmes et al., 2015; Jørgensen et al., 2018). This lack of periodicity with little or no correlation over time is what prevent to predict the behaviour of variables and components in microbial communities and ecosystems (Strogatz, 2007). Many projects study AMR following linear dynamics (e.g. growth curves studies), while systems in reality are non-linear remaining poorly understood. Acquired resistance, from acquisition of foreign resistance genes often located in mobile genetic elements passed vertically and horizontally (intra- and interspecific) within the same or related species of bacteria (Martínez and Baquero, 2014; Kraemer et al., 2019), is an example of such aperiodic non-linear behaviour. Horizontal gene transfer (HGT) makes resistance genes available among microbial communities that temporarily or permanently share habitat and location (Martínez, 2012; Bengtsson-Palme et al., 2018) with unpredictable exchanges and outcomes. HGT is among the most important non-linear dynamics in resistance evolution (Table 1) jointly with long-distance transmission of strains because of trips and social connectivity (Frost et al., 2019; Hernández-García et al., 2019) (Table 1). Other complex dynamics also lead to treatment failure with similar clinical outcomes as resistance (Table 1), but they are often not being considered to assess the risk in treatability for global public health 


\section{The Anthropocene Operating Space for antimicrobial resistance: tipping points in treatability of priority pathogens}

as there are gaps of knowledge within and among them and the majority are still being studied, such as heteroresistance (Andersson et al., 2019).

Careful surveillance of AMR is fundamental to understanding the current context and public health situation. ESKAPE list (Enterococcus faecium, Staphylococcus aureus, Klebsiella pneumoniae, Acinetobacter baumannii, Pseudomonas aeruginosa and Enterobacter spp) (Rice, 2008; Boucher et al., 2009) is among the initial frameworks of problematic priority microorganisms to surveil worldwide but tracking lists have been enlarged since 2008 and monitored pathogens can vary across locations depending on resistance rates (https://resistancemap.cddep.org/AntibioticResistance.php).

In addition to monitoring AMR phenotypically, knowledge of mechanisms and specific genetic resistances involved, including well described detection guidelines, is also crucial for understanding the AMR context (Martinez- and Simonsen, 2017).

Increasing AMR has put in the spotlight frameworks for resistant microorganisms that urgently need innovative therapies or new drugs (CDC_2019; WHO_2017). Despite that, industry and large pharmaceutical companies are not investing enough in this research and these tasks have been devolved upon public universities or public research organizations (Vila et al., 2019).

Table 1: Non-linear dynamics in antibiotic and antimicrobial resistance and their role in treatment failure or clinical adverse outcomes.

\begin{tabular}{|c|c|c|}
\hline TYPE OF DYNAMIC & SIGNFICANCE & REFERENCES \\
\hline $\begin{array}{l}\text { Horizontal Gene } \\
\text { Transfer (HGT) of } \\
\text { resistance genes }\end{array}$ & $\begin{array}{l}\text { Transference of antibiotic resistance gene(s), whose acquisition allows growth } \\
\text { at high concentrations of the antibiotic irrespectively of the time and exposure } \\
\text { duration, through mobile genetic elements between different strains within the } \\
\text { same or different species. }\end{array}$ & $\begin{array}{l}\text { (Stokes and Gillings, 2011; Perry } \\
\text { and Wright, 2013) }\end{array}$ \\
\hline $\begin{array}{l}\text { Co-selection of } \\
\text { resistance }\end{array}$ & $\begin{array}{l}\text { Other stressors present in a defined environment (antimicrobials, heavy metals } \\
\text { or biocides) co-select for antibiotic resistance as resistance genes to these are } \\
\text { often located together in mobile genetic elements. }\end{array}$ & $\begin{array}{l}\text { (Gullberg et al., 2014; Cheng et } \\
\text { al., 2019) }\end{array}$ \\
\hline $\begin{array}{l}\text { Cross-resistance to } \\
\text { other antimicrobials }\end{array}$ & $\begin{array}{l}\text { A specific biocide or drug resistance select also for resistance to other } \\
\text { antimicrobials or antibiotics. It often affects, but not only, antimicrobials with } \\
\text { similar targets or inside the same class. }\end{array}$ & $\begin{array}{l}\text { (Ferretti et al., 2016; Hashemi et } \\
\text { al., 2019) }\end{array}$ \\
\hline $\begin{array}{l}\text { Selection at very low } \\
\text { concentration of } \\
\text { antimicrobials }\end{array}$ & $\begin{array}{l}\text { Selective pressure towards antibiotic resistance at several hundred fold below } \\
\text { the lethality for susceptible cells which can be found in natural environments, } \\
\text { sewage plants, body and cell compartments. }\end{array}$ & $\begin{array}{l}\text { (Gullberg et al., 2011; Wistrand- } \\
\text { Yuen et al., 2018) }\end{array}$ \\
\hline Tolerance & $\begin{array}{l}\text { Induced dormancy or cease of an essential process of a whole bacterial } \\
\text { population that is triggered by stressful conditions. It enables temporary } \\
\text { survival to bactericidal antimicrobials at concentrations that would be lethal. }\end{array}$ & $\begin{array}{l}\text { (Brauner et al., 2016; Levin- } \\
\text { Reisman et al., 2019) }\end{array}$ \\
\hline Persistence & $\begin{array}{l}\text { Reversible phenotype characterized by slow metabolism or dormancy of a } \\
\text { subpopulation inside a main population of bacteria. It enables survival of the } \\
\text { persister subpopulation(s) despite having genetic susceptibility, and after the } \\
\text { stress, persisters grow normally and they can re-establish infection. }\end{array}$ & $\begin{array}{l}\text { (Brauner et al., 2016; Fisher et } \\
\text { al., 2017) }\end{array}$ \\
\hline Heteroresistance & $\begin{array}{l}\text { Unstable phenotype caused by reversible spontaneous genetic modifications } \\
\text { that lead to antimicrobial susceptibility reduction. This reduction affects } \\
\text { subpopulation(s) of a main bacterial population and it could contribute to } \\
\text { adverse clinical outcomes. }\end{array}$ & $\begin{array}{l}\text { (Andersson et al., 2019; Nicoloff } \\
\text { et al., 2019) }\end{array}$ \\
\hline Biofilms & $\begin{array}{l}\text { Structures where bacteria surround themselves with a polymeric matrix that } \\
\text { grows thicker and embeds other microorganisms developing to a complex } \\
\text { structure where cells are protected. Most chronic infections involve biofilms, } \\
\text { as only antibiotics are often ineffective with them. }\end{array}$ & $\begin{array}{l}\text { (Monroe, 2007; Ciofu and } \\
\text { Tolker-Nielsen, 2019; Cabrera et } \\
\text { al., 2020) }\end{array}$ \\
\hline $\begin{array}{l}\text { Long-distance } \\
\text { transmission }\end{array}$ & $\begin{array}{l}\text { Travels and high connectivity allow bottom-up scale transmission of infectious } \\
\text { diseases from local to global and between distant places in short periods of time. }\end{array}$ & $\begin{array}{l}\text { (Frost et al., 2019; Hernández- } \\
\text { García et al., 2019) }\end{array}$ \\
\hline
\end{tabular}

Without new antimicrobials in the market, emergence and rapid spread of resistance in the last decade set the need for common worldwide classifications to describe microorganisms becoming problematic. The first framework widely used standardized the definitions for multidrug-resistant (MDR), extensively drug-resistant (XDR) and pandrug-resistant (PDR) bacteria using guidelines of clinical breakpoints for Staphylococcus aureus, Enterococcus spp., 


\section{The Anthropocene Operating Space for antimicrobial resistance: tipping points in treatability of priority pathogens}

Enterobacteriaceae (except for Salmonella and Shigella), Pseudomonas aeruginosa and Acinetobacter spp. (Magiorakos et al., 2012).Other pathogens such as mycobacteria, Salmonella spp., or Neisseria gonorrhoeae can also be classified by it (Parry and Threlfall, 2008; Hendriksen et al., 2009; Richter et al., 2009; Tapsall et al., 2009; Magiorakos et al., 2012). Acquired non-susceptibility to at least one agent in three antimicrobial categories describes MDR. Acquired non-susceptibility to at least one agent in all but two or fewer antimicrobial categories defines XDR, whereas non-susceptibility to all antimicrobial agents defines PDR. Given that, simple drug-resistance can be thought as the natural susceptible pattern of a wild-type microorganism. Proposed more recently, the Anthropocene Operating Space (AOS) of biocide susceptibility framework classifies microorganisms using the precautionary risk of planetary boundaries (Jørgensen et al., 2018). Planetary boundaries define and delimit key functions and tipping points using assessments of the impacts of human activities on systems (Steffen et al., 2015). Planetary boundaries focus on areas and processes of the system that determine the self-regulating capacity of the planet and where humans can safely operate. This concept incorporates tipping points or thresholds related to processes and reaching or crossing those can trigger non-linear abrupt changes in the functioning of the system, with risk of sudden and irreversible changes, thereby diminishing resilience from regional to global consequences (Steffen et al., 2015). The AOS assessed the state and governance priorities of biocide susceptibility at general level of Gram-positive and Gramnegative bacteria, using zones of increasing risk for current antimicrobial practices: 'safe', 'uncertain' and 'surpassed' (Jørgensen et al., 2018). No relevant resistance or presence of single biocide resistance at low frequencies and with many other available biocides falls into 'safety' whereas 'uncertainty' is entered when less desirable treatments must be applied due to multiple resistance or when single resistance is common but few alternatives are available. Therefore, when resistance is observed to all relevant therapies (pan-resistance) the surpassed zone is entered (Jørgensen et al., 2018).

As it is shown, multiple classifications exist for ranking resistance in terms of sizing the threat and urgency for taking action but global application of them is difficult as they apply heterogeneous and specific criteria. In our comprehensive study, well-known established classifications of AMR, non-linear dynamics of ecosystems involved in resistance and riskassessment of current tipping points in treatability, based on updated literature search, at the level of priority pathogens have been integrated in a holistic framework for public health use. This framework called the Anthropocene Operating Space for Antimicrobial Resistance (AOS for AMR) can be used, alone or with other frameworks, in a 'One Health' context and across sectors to inform and to warn of the current situation and limitations where we can safely operate and maintain effective therapies. While advising towards global sustainable policies, from a worldwide perspective, the AOS for AMR details the current situation of 20 priority pathogens for global public health protection purposes.

\section{Methodology}

\section{a. Identifying a set of priority organisms for assessment}

Microorganisms at individual level were identified and assessed in this study for risk of tipping points in resistance associated with remaining efficacious antibiotics. This selection compares and combines some of the major important and well-established surveillance frameworks in human medicine on a global scale or on supranational or large national organizations (Table 2). However, not all regions and countries are equally represented or have robust surveillance 


\section{The Anthropocene Operating Space for antimicrobial resistance: tipping points in treatability of priority pathogens}

systems. Low-middle-income countries (LMICs) in Asia, Africa and South-America often cope with multiple challenges, if they do have those systems (Ashley et al., 2018). The major surveillance system stablished worldwide is the Global Antimicrobial Resistance Surveillance System hosted by the World Health Organization (WHO) that gathers AMR data of 8 bacteria (WHO, 2017) (Table 2). Moreover, big supranational organizations (e.g. in Europe different programs inside The European Surveillance System) and national surveillance programmes of large countries (e.g. United States Centers for Disease Control and Prevention (US CDC)) were considered to identify and compare microorganisms commonly tracked (Table 2).

Apart from surveillance, new approaches or new drugs are urgently needed for pathogens identified by WHO in its list of pathogens for which new antibiotics are urgently needed and by US CDC in its estimations of cases/infections and deaths per year caused by resistant microorganisms (Table 3) (CDC_2019; WHO_2017).

Table 2: Microorganisms tracked in antimicrobial resistance surveillance programmes sponsored by health organizations worldwide. AGAR= Australian Group on Antimicrobial Resistance, AGSP = Australian Gonococcal Surveillance Programme, ARLN= CDC Antibiotic resistance Lab Network, AESOP= Australian Enterococcal Sepsis Outcome Program, ASSOP= Australian Staphylococcal Sepsis Outcome Program, CAESAR = Central Asian and Eastern European Surveillance of Antimicrobial Resistance, US CDC $=$ Centers for Disease Control and Prevention in United States, EARS-Net= European Antimicrobial Resistance Surveillance Network, ECDC = European Centre for Disease and Control, ECDIS-Net= European Clostridium difficile Infection Network project, EURGen-Net= European Antimicrobial Resistance Genes Surveillance Network, Euro-GASP= European Gonococcal Antimicrobial Surveillance Programme, FWD-Net= European Food- and Waterborne Diseases and Zoonosis Network, GISP= Gonococcal Isolate Surveillance Project, GLASS= Global Antimicrobial Resistance Surveillance System, GNSOP= Gram Negative Sepsis Outcome Program, NARMS= National Antimicrobial Resistance Monitoring System for Enteric Bacteria in the US, TME= WHO Tuberculosis Monitoring and Evaluation platform, WHO= World Health Organization, GASP= WHO Gonococcal Antimicrobial Surveillance Programme, $*=$ including also other Enterobacteriaceae, $\mathrm{a}=\mathrm{starting}$ from $2020 / 2021, \S=$ Shiga toxin producing Escherichia coli (STEC), $\S \S$ sponsored by the Australian Government- Department of Health, ${ }^{\mathrm{a}}=$ and European Food Safety Authority (EFSA).

\begin{tabular}{|c|c|c|c|c|c|c|}
\hline & \multirow[b]{3}{*}{ Microorganism } & \multicolumn{5}{|c|}{ Sponsor or collaborative organizations of surveillance systems } \\
\hline & & Global & \multicolumn{2}{|c|}{ International } & \multicolumn{2}{|c|}{ National } \\
\hline & & WHO & ECDC & WHO-RIVM-ESCMID & US CDC & AGAR \\
\hline \multirow{8}{*}{$\begin{array}{l}\text { Gram } \\
\text { Negative } \\
\text { bacteria }\end{array}$} & Klebsiella pneumoniae & GLASS & $\begin{array}{c}\text { EARS-Net } \\
\text { /EURGen-Net* }\end{array}$ & CAESAR & ARLN* & GNSOP* \\
\hline & Acinetobacter spp. & GLASS & $\begin{array}{c}\text { EARS-Net } \\
\text { /EURGen-Net x }\end{array}$ & CAESAR & ARLN & GNSOP \\
\hline & Pseudomonas aeruginosa & & EARS-Net & CAESAR & & GNSOP \\
\hline & Escherichia coli & GLASS & $\begin{array}{c}\text { EARS-Net } \\
\text { /EURGen-Net* } \S \\
/ \text { FWD-Net } \S^{\mathrm{a}}\end{array}$ & CAESAR & $\begin{array}{c}\text { ARLN*/NARM } \\
\mathrm{S}\end{array}$ & GNSOP* \\
\hline & Neisseria gonorrhoeae & $\begin{array}{l}\text { GLASS/ } \\
\text { GASP }\end{array}$ & Euro-GASP & & ARLN/GISP & AGSP§§ \\
\hline & Salmonella spp. & GLASS & FWD-Net ${ }^{\mathrm{a}}$ & CAESAR & ARLN/NARMS & \\
\hline & Shigella spp. & GLASS & & & NARMS & \\
\hline & Campylobacter & & FWD-Net $^{\mathrm{a}}$ & & NARMS & \\
\hline \multirow{4}{*}{$\begin{array}{l}\text { Gram } \\
\text { Positive } \\
\text { bacteria }\end{array}$} & Staphylococcus aureus & GLASS & EARS-Net $^{a}$ & CAESAR & & ASSOP \\
\hline & $\begin{array}{c}\text { Streptococcus } \\
\text { pneumoniae }\end{array}$ & GLASS & & CAESAR & ARLN & AESOP \\
\hline & Enterococcus spp. & & EARS-Net & CAESAR & & \\
\hline & Clostridioides & & ECDIS-Net & & ARLN & \\
\hline $\begin{array}{l}\text { Other } \\
\text { bacteria }\end{array}$ & $\begin{array}{c}\text { Mycobacterium } \\
\text { tuberculosis }\end{array}$ & TME & $\begin{array}{c}\text { Tuberculosis Disease } \\
\text { Network }\end{array}$ & & ARLN & \\
\hline Fungi & Candida spp. & & & & ARLN & \\
\hline
\end{tabular}

Table 3: Urgent threats that require new available antibiotics. US CDC $=$ Centers for Disease Control and Prevention, $\mathrm{CR}=\mathrm{Carbapenem}$ Resistant, $\mathrm{C} 3 \mathrm{G}=$ Third generation Cephalosporin, $\mathrm{FQ}=$ Fluoroquinolone, ESBL= Extended Spectrum B-Lactamase, MDR= Multidrug Resistant, MRSA= Methicillin Resistant Staphylococcus aureus, NA = Not assessed, R= Resistant, VISA= Vancomycin- Intermediate Staphylococcus aureus, VRSA= Vancomycin Resistant Staphylococcus aureus, VRE= Vancomycin Resistant Enterococcus, WHO= World Health Organization, XDR= Extensively-drug Resistant, ${ }^{*}=$ not assessed but considered critical.

WHO

Microorganism (s)

Gram Negative Enterobacteriaceae bacteria

\section{WHO}

Threat level

Critical

Critical

\begin{tabular}{|l|l|}
\hline $\begin{array}{l}\text { Resistance } \\
\text { mechanism / profile }\end{array}$ & $\begin{array}{l}\text { Threat } \\
\text { level } \\
\text { Critical }\end{array}$ \\
\hline CR & Serious \\
\hline CR & \\
\hline
\end{tabular}

US CDC
Critical

Serious

\begin{tabular}{l}
$\begin{array}{l}\text { Resistance } \\
\text { mechanism / profile }\end{array}$ \\
\hline CR \\
\hline MDR/XDR
\end{tabular}

MDR/XDR 


\section{The Anthropocene Operating Space for antimicrobial resistance: tipping points in treatability of priority pathogens}

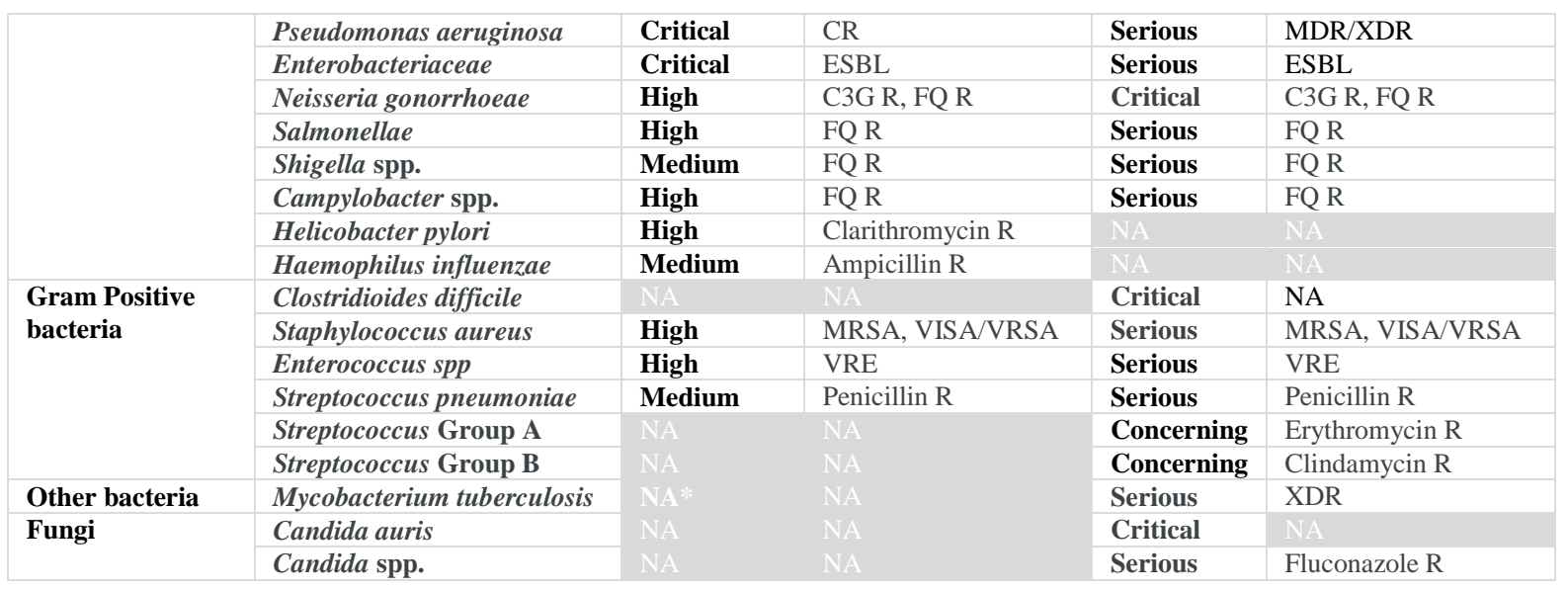

b. Operationalization, criteria and categories of the Anthropocene Operating Space for Antimicrobial Resistance (AOS for AMR)

To operationalize the framework at the level of individual pathogens, the commonly used MDR-XDR-PDR framework and the AOS framework were integrated (Table 4) (Magiorakos et al., 2012; Jørgensen et al., 2018).

Table 4: Operationalization of the Anthropocene Operating Space framework for Antimicrobial Resistance (AOS for AMR). AMR= antimicrobial resistance; $\mathrm{AOS}=$ Anthropocene Operating Space; MDR= Multidrug resistance; PDR=pandrug resistance; SDR= simple drug resistance; $\mathrm{XDR}=$ extensively-drug resistance.

\begin{tabular}{||c|c|c|}
\hline \multicolumn{2}{|c|}{ FRAMEWORK } \\
\hline $\begin{array}{c}\text { MDR-XDR-PDR + AOS } \\
\text { INTEGRATION }\end{array}$ & AOS for AMR \\
\hline PDR & Surpassed zone & Surpassed zone: Therapy unavailable (resistance is observed to all relevant biocides) \\
\hline \hline XDR / MDR & Uncertain zone & $\begin{array}{c}\text { Uncertain zone: Less desirable therapies or few alternatives (multiple biocide } \\
\text { resistance is observed or single biocide resistance is common with few alternatives) }\end{array}$ \\
\hline \hline SDR & Safe zone & $\begin{array}{c}\text { Safe zone: Therapy available (no relevant resistance / presence of single biocide } \\
\text { resistance at low frequencies ) }\end{array}$ \\
\hline
\end{tabular}

The final operationalization divided the uncertain zone into 3 areas ending up in five zones (Table 5) to better adapt the complexity of AMR not reflected in the initial categorization. The chosen criteria for this new organization (by importance) are: (i) Reported acquired resistance in literature; and (ii) threat level and priority for new drugs (Table 3). The first criteria implies that selected microorganisms tracked have already acquired mechanisms of resistance that have also been detected and described in literature. To be used for public health protection purposes, when acquired resistance at the level of MDR, XDR and PDR is well-described in literature the species is categorized according to this profile independently of the percentage of strains having this resistance pattern. Therefore, a literature search was done for each pathogen looking for PDR ('(pandrug or pan-drug) and resistance' or 'pan-resistance or panresistance'). Otherwise, the search was focused on the next level, XDR. If XDR was not described, finally the literature search was done looking for MDR. The second criteria emphasizes the importance of innovation in medicine to have available therapies to treat infections and to ensure clinical procedures that rely on antibiotics. Depending on the risk of treatability being compromised, final categories were: (i) surpassed zone, (ii) uncertain zone high risk area, (iii) uncertain zone medium risk, (iv) uncertain zone low risk; and (v) safe zone.

Table 5: Decision criteria for the Anthropocene Operating Space for Antimicrobial Resistance framework (assessment based on Table 3 and Table 4). AMR= antimicrobial resistance; AOS =Anthropocene Operating Space; MDR= Multidrug resistance; PDR=pandrug resistance; $\mathrm{SDR}=$ simple drug resistance; $\mathrm{XDR}=$ extensively drug resistance; $\mathrm{R}=$ resistance. 


\section{The Anthropocene Operating Space for antimicrobial resistance: tipping points in treatability of priority pathogens}

\begin{tabular}{||c|c|c|}
\hline \multicolumn{2}{|c|}{ CRITERIA } & ASSESSMENT \\
\hline HIGHEST R REPORTED & THREAT LEVEL, PRIORITY FOR NEW DRUGS & AOS for AMR \\
\hline PDR & All cases & Surpassed zone \\
\hline XDR & Critical & Surpassed zone \\
XDR & Serious or High & Uncertain zone: high risk \\
XDR & Concerning or Medium & Uncertain zone: medium risk \\
\hline MDR & Critical & Uncertain zone: medium risk \\
MDR & Serious or High & Uncertain zone: low risk \\
\hline \hline SDR & Concerning or Medium & Safe zone \\
\hline
\end{tabular}

220

\section{Results: risk assessment of tipping points in treatability for priority pathogens}

Here we assess the current risk of tipping points in priority pathogens (Table $\mathbf{2}$ and $\mathbf{3}$ ) according to the operationalized AOS for AMR framework (Table 5). The final assessment is specified in Table 6 and Figure 1 with the latter showing the planetary boundary regions.

The first level of risk is the 'surpassed zone' which includes microorganisms whose treatability is already compromised because the tipping point has been surpassed. In the surpassed category there are 7 out of 20 pathogens assessed 6 Gram- negative bacteria (GNB) and 1 fungi being them: (I) Acinetobacter genus, (II) Pseudomonas aeruginosa (P.aeruginosa), (III) Escherichia coli (E.coli), (IV) Klebsiella pneumoniae (K.pneumoniae), (V) other Enterobacteriaceae (without Salmonella and Shigella) at community or hospital level, (VI) Neisseria gonorrhoeae (N.gonorrhoeae) at community level and (VII) the yeast Candida auris (C.auris) at hospital level.

The uncertain zone covers a range of increasing risk of treatability being compromised. It comprises 3 areas of risk (high, medium, low) and the rest of pathogens assessed (13 out of 20). All priority Gram-positive bacteria (GPB) pathogens are inside this area (6 out of 20).

The second level of the AOS for AMR is the uncertain high risk area which is just reaching the tipping point and where microorganisms are at high risk of surpassing it. It includes 5 pathogens out of the 13 inside uncertainty, and, 5 out of the 20 assessed. In this category we find (I) Salmonella, (II) Mycobacterium tuberculosis (TB) and the firsts GPB until now. (III) Clostridioides difficile (C.difficile), (IV) Staphylococcus aureus (S.aureus) and (V) the genus Enterococcus. .

The third level includes 6 pathogens inside the uncertain zone medium risk implying that the tipping point can be reached by those pathogens. It is the most heterogeneous sub-zone with MDR and XDR pathogens and serious/high or concerning/medium priority for new drugs. It includes the fungal genus (I) Candida (except $C$.auris assessed inside the first level-surpassed); the GNB genera (II) Shigella and (III) Campylobacter, the species (IV) Helicobacter pylori (H.pylori), (V) Haemophilus influenzae (H.influenzae) and the GPB (VI) Streptococcus pneumoniae (S.pneumoniae).

The fourth level closes the uncertain area with low risk and it only includes GPB pathogens (2 out of 13). This fourth level implies availability of therapies but increasing resistance to key and critical antibiotics of microorganisms that have left the safe zone. (I) Streptococcus group A (GAS) and (II) Streptococcus group B (GBS) belong to this sub-zone.

The fifth level in riskiness or 'safe zone' is the wild-type susceptibility or intrinsic resistance of microorganisms that could fit in the safe area in Figure $\mathbf{1}$ and probably it includes most microorganisms not mentioned in Table 6. 


\section{The Anthropocene Operating Space for antimicrobial resistance: tipping points in treatability of priority pathogens}

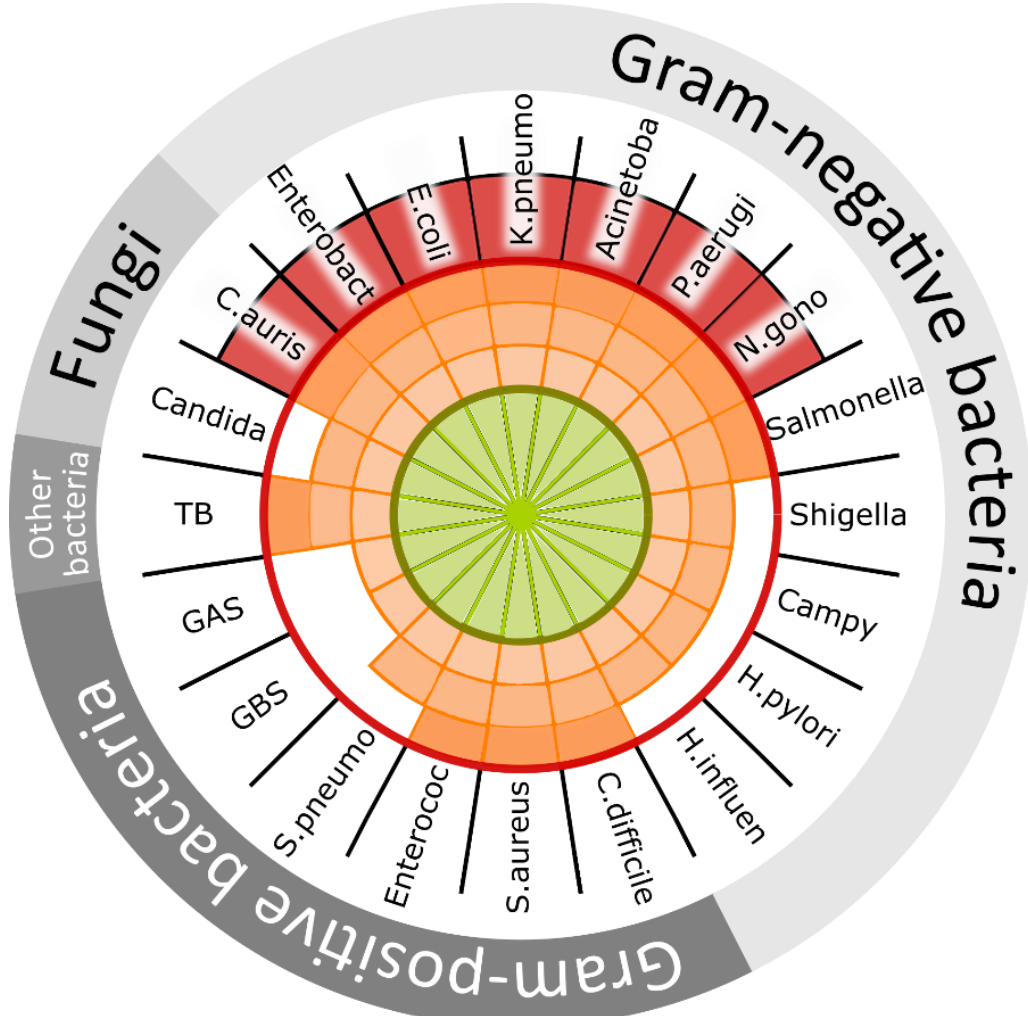

Surpassed zone

Tipping point: surpassed-uncertain border

Uncertain high-risk zone

Uncertain medium-risk zone

Uncertain low-risk zone

Safe-uncertain border

Safe zone

Figure 1: Current global status of treatability in selected pathogens using the Anthropocene Operating Space for Antimicrobial Resistance framework. Acinetoba= Acinetobacter genus; C.difficile $=$ Clostridioides difficile; Campy=Campylobacter genus; Candida $=$ Candida genus except Candida auris; C.auris = Candida auris; Enterobact = Enterobacteriaceae family except Escherichia coli, Klebsiella pneumoniae and genera Salmonella and Shigella; Enterococ= Enterococcus genus; E.coli= Escherichia coli; GAS= Streptococcus Group A; GBS= Streptococcus Group B; H.influen= Haemophilus influenzae; H.pylori= Helicobacter pylori; K.pneumo= Klebsiella pneumoniae; N.gono= Neisseria gonorrhoeae; P.aerugi= Pseudomonas aeruginosa; Salmonella= Salmonella genus; Shigella= Shigella genus; $\mathrm{S}$. pneumo= Streptococcus pneumoniae; S.aureus= Staphylococcus aureus; TB= Mycobacterium tuberculosis .

Table 6: Assessment of tipping points in treatability in selected pathogens using the Anthropocene Operating Space for Antimicrobial Resistance (AOS for AMR) framework based on Table 5. HR= high risk, LR= low risk MR= medium risk, MDR= Multidrug resistance; PDR=pandrug resistance; XDR=extensively-drug resistance. *= except Escherichia coli, Klebsiella pneumoniae, and genus Salmonella and Shigella.

\begin{tabular}{|c|c|c|c|c|c|}
\hline & Microorganism(s) & $\begin{array}{l}\text { AOS for AMR } \\
\text { assessment }\end{array}$ & $\begin{array}{l}\text { Reported } \\
\text { resistance }\end{array}$ & $\begin{array}{c}\text { Innovation } \\
\text { need } \\
\text { (Table 3) }\end{array}$ & References \\
\hline \multirow{11}{*}{$\begin{array}{l}\text { Gram } \\
\text { Negative } \\
\text { bacteria }\end{array}$} & Acinetobacter spp. & Surpassed & PDR & Critical & $\begin{array}{l}\text { (Rolain et al., 2013; Göttig et al., 2014; Nowak et al., } \\
\text { 2017) }\end{array}$ \\
\hline & Pseudomonas aeruginosa & Surpassed & PDR & Critical & $\begin{array}{l}\text { (Khosravi and Mohammadian, 2016; Shokri et al., } \\
\text { 2016) }\end{array}$ \\
\hline & Klebsiella pneumoniae & Surpassed & PDR & Critical & (Avgoulea et al., 2018) \\
\hline & Escherichia coli & Surpassed & PDR & Critical & (Kim et al., 2019) \\
\hline & $\begin{array}{l}\text { Enterobacteriaceae* (e.g. } \\
\text { Enterobacter, Citrobacter, Proteus, } \\
\text { Morganella, Providencia, Serratia) }\end{array}$ & Surpassed & PDR & Critical & (Gruber et al., 2014; Hernández-García et al., 2018) \\
\hline & Neisseria gonorrhoeae & Surpassed & XDR & Critical & (Cámara et al., 2012; ECDC, 2018) \\
\hline & Salmonella spp. & Uncertain: HR & XDR & Serious & $($ EFSA-ECDC, 2020$)$ \\
\hline & Shigella spp. & Uncertain: MR & MDR & Serious & (Puzari et al., 2018) \\
\hline & Campylobacter spp. & Uncertain: MR & MDR & Serious & (Sproston et al., 2018; EFSA-ECDC, 2020) \\
\hline & Helicobacter pylori & Uncertain: MR & MDR & High & (Boyanova et al., 2019) \\
\hline & Haemophilus influenzae & Uncertain: MR & XDR & Medium & (Su et al., 2020) \\
\hline \multirow{3}{*}{$\begin{array}{l}\text { Gram } \\
\text { Positive } \\
\text { bacteria }\end{array}$} & Clostridioides difficile & Uncertain: HR & MDR & Critical & (Peng et al., 2017) \\
\hline & Enterococcus spp. & Uncertain: HR & XDR & Serious & (Said and Abdelmegeed, 2019) \\
\hline & Staphylococcus aureus & Uncertain: HR & XDR & Serious & (Cabrera et al., 2020) \\
\hline
\end{tabular}




\section{The Anthropocene Operating Space for antimicrobial resistance: tipping points in treatability of priority pathogens}

\begin{tabular}{|c|c|c|c|c|c|}
\hline & Streptococcus pneumoniae & Uncertain: MR & MDR & Serious & (Cillóniz et al., 2018) \\
\hline & Streptococcus Group A & Uncertain: LR & MDR & Concerning & (Ferretti et al., 2016) \\
\hline & Streptococcus Group B & Uncertain: LR & MDR & Concerning & (Moraleda et al., 2018) \\
\hline Other & Mycobacterium tuberculosis & Uncertain: HR & XDR & Serious & $(\mathrm{ECDC}, 2019)$ \\
\hline \multirow[b]{2}{*}{ Fungi } & Candida spp. & Uncertain: MR & MDR & Serious & (Arendrup and Patterson, 2017) \\
\hline & Candida auris & Surpassed & PDR & Critical & (Lockhart et al., 2017; Ostrowsky et al., 2020) \\
\hline
\end{tabular}

a. The practical species level and lower levels of public health concern

272 Many frameworks flag pathogens in different ways and with different objectives making their use difficult to apply across sectors. Hence, our study comprehends the most used and important AMR classifications assessing the current situation in treatability to describe a new framework -AOS for AMR- with global scale application at the level of species or genera. The 'ESKAPE' pathogens, whose name was a wink to the ability of bacteria to 'escape' antimicrobial exposure thanks to high abundance of mobile genetic elements and frequent genetic exchanges via HGT (Boucher et al., 2009), raised awareness of even lower levels of public health concern: mobile resistance genes and high risk clones.

On one hand, among the most worrisome mobile resistance genes, there are: (i) extendedspectrum $\beta$-lactamases (ESBLs), (ii) carbapenemases and (iii) mobile colistin resistance ( $\mathrm{mcr}$ ) genes. The first two encode for $\beta$-lactamase enzymes that lead to, at least, multi-drug resistance to the $\beta$-lactam class of antibiotics. ESBLs hydrolyse $\beta$-lactams excluding cephamycins and carbapenems (Ur Rahman et al., 2018) being CTX-M among the most widespread, both geographically and among human/animals (Cantón et al., 2012; Woerther et al., 2013). Carbapenemases confer resistance to carbapenems (last resort $\beta$-lactam with the broadest spectrum of action). Carbapenemases are classified in three groups with different distribution globally (van Duin and Doi, 2017): (i) Ambler Class A like K.pneumoniae carbapenemase (KPC), commonly found in the United States and in Mediterranean countries; (ii) Ambler Class B like New Delhi, Verona-integron and imipenem-resistant Pseudomonas metallo- $\beta$ lactamases (NDM, VIM and IMP, respectively) common in the Indian subcontinent and in some European countries; and (iii) Ambler Class D OXA-48-like carbapenemases (e.g. OXA48, OXA-181, OXA-23), whose ability to mutate and expand their spectrum of activity is remarkable, are mainly found in Turkey and Middle-East. Nonetheless, travels to endemic regions and nosocomial outbreaks have faded away geographical barriers and all being reported worldwide (e.g. Hernández-García et al., 2019). The last highlighted mobile resistance genes, $m c r$ genes, encode for colistin resistance, a last resort drug with severe side effects also used in veterinary medicine (Liu et al., 2016). Ten $\mathrm{mcr}$ genes ( $\mathrm{mcr}-1$ to $\mathrm{mcr}$ - 10 ) have been described (Wang et al., 2020). First detected in 2015 from pigs ( $m c r-1$ ), $m c r$ genes were soon widespread across the 'One Health' spectrum (Skov and Monnet, 2016). On the other hand, high risk clones are clone-clusters inside species whose identification relies on species-specific molecular typing techniques. High risk clones are extremely overrepresented among clinical isolates and they have enhanced global dissemination of mobile resistance genes (both intra- and interspecies) helped by selective pressure in hotspots (Mathers et al., 2015).

Although, mobile resistance genes and high risk clones are remarkably important in AMR, from a realistic view and practical usage, their identification requires time, technical personnel and specific facilities not available everywhere, especially in LMICs or small hospital labs. For global public health, the application of the AOS for AMR framework at the level of species or genera is much more suitable, practical and feasible because identification at this level is easier, 


\section{The Anthropocene Operating Space for antimicrobial resistance: tipping points in treatability of priority pathogens}

cheaper and routinely done in most laboratories worldwide, including those countries with less income resources. Assessment of the most worrisome resistance concerns at species/genera level (Table 6), such HGT and high risk clones, and non-linear dynamics (Table 1) have been considered to contextualize the AOS for AMR. However, defining every resistance mechanism, for every antimicrobial and pathogen is beyond of the scope of this framework. Overall, our assessment points out that GNB (whose cell wall differs from GPB or mycobacteria) are the most remarkable exceeding our limits to safely maintain treatability accounting for 11 out of the 20 pathogens assessed, and 6 having already crossed the tipping point. Moreover, our assessment concludes that XDR and PDR infections caused by pathogens in the surpassed zone or inside the uncertain high-risk zone represent a huge risk for sustaining available therapies. Those lack of options in treatability involve contact prevention-isolation measures, higher lengths of stay in hospitals or much more expensive associated costs impacting significantly on mortality and morbidity (Kousouli et al., 2019).

\section{b. AOS for AMR: current state, drivers and resilience for sustained treatability}

Defining AMR is not easy and it is difficult to categorize microorganisms that, if not fully resistant, need much higher doses of antibiotics to be effective with a risk of more severe side effects. This can also be seen as a sign of the decreasing set of options that prescribers have to treat infections. And with the growth in use of second-line or last resort antibiotics (for MDR and XDR infections often dosed intravenous or intramuscular needing trained professionals and hampering accessibility. Protected drugs, combination of drugs or drugs still on trial (for PDR infections) often have undesirable side effects leading to higher mortality rates (Aslam et al., 2018; Klein et al., 2018; Karaiskos et al., 2019; Tsala et al., 2019). The AOS for AMR can make more understandable to everyone, even citizenship, that MDR or XDR pathogens can also be jeopardizing treatability. They send a false sense of 'security' because they still have treatment available but they might be on the edge of crossing the tipping point (e.g. if XDR turns easily to PDR). As this framework is aimed to be applied for priority pathogens at level of species or genera, it is interesting to point out that XDR of problematic pathogens can be categorized within the 'uncertain zone' per definition but when strains can overstep to the 'surpassed zone', those XDR strains can be considered at the level of PDR in treatability (e.g. Acinetobacter susceptible only to the last resort antibiotic colistin and with high probability to develop resistance (Mustapha et al., 2018; Trebosc et al., 2019)). The AOS for AMR categories can be a useful concept for health and non-health professionals, the latter less familiar with antimicrobials categories and implications of different use.

Considering the specific features of all mentioned classifications, there is one big similarity within them: the aim to optimize monitoring and global epidemiological surveillance while pointing out risks of increasing AMR worldwide. Resistance rates may be under- or overestimated due to lack of surveillance data world-wise although reported mechanisms may be accurate. Surveillance systems in human health have limited resources and low coverage in LMICs, especially in regions inside Africa, Asia and South America, because resistance diagnostics are cornered to research centres, universities or pharma industry and they face challenges such low coverage, selective sampling and underfunding (Ashley et al., 2018). However, the application of our framework in countries with incipient or low coverage surveillance is not an impediment. Finding a pathogen with an unreported MDR, XDR or PDR profile can categorize the pathogen inside the framework or in a higher level and warn about 


\section{The Anthropocene Operating Space for antimicrobial resistance: tipping points in treatability of priority pathogens}

resistance, not in an alarming but in a guarding way to inform rapidly and globally. If AMR surveillance in human healthcare has low coverage in LMICs, the challenge of AMR surveillance in animals is even harder and, if exists, it is based on point-prevalence surveys (Van Boeckel et al., 2019). Interestingly, AMR surveillance in animals has not stood out as strongly as in humans in LMICs, although the majority of the antimicrobials (up to 73\%) are used in husbandry consequence of the worldwide growing demand for animal protein (Van Boeckel et al., 2019). Correlation between antibiotic usage and resistance seems obvious, being the most used antimicrobials in farming (tetracyclines, sulphonamides and penicillins) the ones with highest resistance rates among animal isolates in LMICs (Van Boeckel et al., 2019) but also observed in several contexts in our assessment such macrolides use and macrolide resistance in H.pylori or Streptococcus (Ferretti et al., 2016; Boyanova et al., 2019). While interplay for survival, competence and resistance against stressors naturally occurs in microbial communities, since the discovery of antibiotics, anthropogenic disturbances have been the major driver for AMR evolution (Jørgensen et al., 2020), especially selection pressure consequence of antimicrobial use Supporting this claim, resistance has also emerged from different locations simultaneously, such as the case of the yeast C.auris, probably consequence of our misuse of antimicrobials during decades (Forsberg et al., 2019)..

Several efforts are done to reduce antimicrobial use but not even complete antimicrobial withdrawal is a silver bullet. Despite absence of antibiotics, once resistance is acquired, it may not be reversed. For example, fluoroquinolones were widely used in husbandry production since the 1980's, but resistance rates led to: (i) restrictions in the European Union (2003 and 2006) and the United States (2005) and (ii) surveillance programs among foodborne pathogens (Sproston et al., 2018). But, AMR data has barely declined trends of fluoroquinolone resistance in Campylobacter isolates from humans (EFSA-ECDC, 2020). Resistance mutations explain their maintenance in an environment with antibiotics but, in the absence of selective pressure, low fitness cost can lead to persistence and expansion due to clonal division. This is also the case of N.gonorrhoeae whose biological fitness does not seem affected by resistance traits, therefore fixing the resistance even when no antibiotic selection pressure is applied (Alirol et al., 2017). Even if those mutations have high fitness cost, in the absence of antibiotic, selection of compensatory mutations can reduce this cost which implies some degree of resistance loss ending with mixed populations of cells like in heteroresistance. Moreover, resistance can have advantages in transmission (biofilm formation in aerobic conditions) and/or pathogenicity (virulence through invasive phenotypes), facts that may help also to resistance stabilization (Ferretti et al., 2016; Whelan et al., 2019). Those aperiodic dynamics for resistance fixation make the framework useful for describing the surpassed or uncertain area in which non-linear dynamics play a role that cannot be foreseen. Campylobacter, N.gonorrhoeae or Streptococcus are examples of resistance fixation within assessed pathogens. Pathogens in the surpassed area have crossed the tipping point. But in the uncertain area, although we may still be inside the planetary boundary, we lack of knowledge to predict the extent and consequences of resistance once acquired.

Following this line, the AOS for AMR also has the aim of warning sternly about the importance of treatment sustainability advising to approach this challenge with a broader view. Because there are several pieces affecting the social-ecological system (SES), including our actions as society, influencing on AMR. The SES is a complex adaptive system strongly driven by anthropogenic ecoevolutionary forces (Jørgensen et al., 2020) but all system connections, how and how much each one interact with each other is poorly understood yet. From the ecological perspective, drivers for AMR evolution also influenced by human activity are, for example, 


\section{The Anthropocene Operating Space for antimicrobial resistance: tipping points in treatability of priority pathogens}

co- selection for resistance lead by stressors (e.g. chlorhexidine) or heavy metals (Gullberg et al., 2014; Jørgensen et al., 2018; Hashemi et al., 2019). Antibiotics are not specific and also affect beneficial microorganisms. Selection pressure is exerted in the whole microbiome unbalancing systems especially when they are affected for long periods. From the social perspective, behaviour plays an important role in driving AMR with (i) Direct actions, for example, safe-sex promotion/awareness can prevent infections (and antibiotic use) enhancing better societal outcomes; or with (ii) Indirect actions, for example, antivaccine movements whose consequences are far-reaching. The SES is also impacted by historical and societal features like: (i) access difficulty to antimicrobials; (ii) the structure of the health system; (iii) support of institutions in surveillance programmes; (iv) awareness of the population; or (v) investments in research and innovation. The latter is basically supported by public institutions, often with scarce funding depending on grants and with small possibilities to go through the expensive last phases of clinical development. Among new strategies in research we can find: (i) new antibiotics (Imai et al., 2019); (ii) new vaccines for community infections (N.gonorrhoeae, Shigella, GBS or H.influenzae); (iii) new methods in clinical microbiology like whole genome sequencing as powerful tool to study the global resistome and improve surveillance (Rolain et al., 2013; Cuypers et al., 2018); (iv) new designs for point-of-care rapid diagnostics (Cruz et al., 2019) or (v) different novel approaches in interventional science (AMResilience (https://amr-resilience.gtglab.net/)). Meanwhile society awaits for innovation, the AOS for AMR gives the grounds to alert about the situation if those new approaches take time. This is key as there are many hopes in new drugs or diagnostics but they may be finally on the market several years from now, and even if they are now out, therapy safety and sustainability may be still in danger.

However, a big change on how address this complex challenge is needed or not even with new approaches we will succeed. Basically, until now, we as society have respond to disturbances but we have not addressed the roots. Disturbances have been rapidly overcome because resistance implies to some extent a fitness cost and because species have a proportional balance in the biome. But, our system disruption is serious and maintained for decades jeopardizing now treatability and the whole health system. This is especially seen with the 7 pathogens inside the surpassed category which have left the safe area. Those pathogens have few high risk clones overtaking the majority of infections in healthcare settings and they account the vast majority of therapeutic dilemmas microbiologists are dealing with trying to respond as best as they can. AMR of species of epidemiological significance within the nosocomial system are often on the spot, whereas AMR in the microbial community is less discussed but it may be affected. With this first assessment of the framework we also emphasize to focus on pathogens that are not always in the spot light. GAS and GBS have already entered the uncertainty area, and 6 pathogens, usually found at community level, are in the medium risk (Shigella, Campylobacter, H.pylori, H.influenzae, the GPB S.pneumoniae and the fungi Candida). Moreover, promotion of heterogeneity and susceptibility of microorganisms in microbial communities is discussed to even a lesser extent. The AOS for AMR has also as objective to promote a big mind-set change going towards treatment sustainability and preservation of antimicrobial effectiveness. We do need new antibiotics, antimicrobials and drugs to have therapeutic options for resistant pathogens, but what we do need the most is acknowledging that actions in society also affect this challenge in the Anthropocene. The AOS for AMR identifies the context of treatability and AMR at a global scale for 20 pathogens but further studies will need to provide the ways in which we can remain in the safe zone.

\section{c. Advantages and limitations}




\section{The Anthropocene Operating Space for antimicrobial resistance: tipping points in treatability of priority pathogens}

The AOS for AMR points out the increasing risk of resistance and available therapy for 20 priority pathogens. Some have crossed the tipping point for treatability (7) and the rest can surpassed it soon (13). This framework relies on two of important parameters at the same time: the clinical epidemiology state and the ecological sustainable goal of maintaining treatability. It can be used across sectors gathering current and updated AMR information for global public health protection. Some of the biggest strengths of this classification is that can be feasibly applied on a bigger scale with little or without economic investment at the level of species or genera even in countries with less economic resources. It can be quickly updated, and it is easily understandable for actors involved in AMR and not only for health professionals. Also, it introduces the concept of planetary boundaries in AMR at species or genera resolution and it encourages to preserve antimicrobials and to build resilience in our health system.

However, our framework has some limitations too. Not all important pathogens are currently assessed in the framework. Only 20 priority pathogens have been assessed, although the list of assessed pathogens including protozoa and virus can be extended in the future. In addition, it can be used but it is not practical in smaller scales (e.g. hospital reports of patients) and in that case the current MDR-XDR-PDR can be more suitable. Another limitation is the risk of misinterpretation when it comes to resistance patterns. This is not a framework thought to generalize about resistance profiles but to be used for health protection purposes. In that sense, not all strains of pathogens assessed in the surpassed zone have a PDR profile but this profile has been found, in more or less proportion in the species, and we must be careful applying precautionary principles.

To our knowledge, the AOS for AMR framework is the first one that can be used between and across different sectors such health professionals, ecologists or policy makers and it warns also society in a dual way: (i) our current epidemiological and treatability situation of bacterial and some fungal infectious diseases; and (ii) advice for considering the SES context to address this global challenge and to maintain the planetary boundary promoting actively awareness and resilience of the health system rather than answering to its disturbances.

\section{d. Current context}

AMR is a dynamic process and resistance can emerge in species that were not worrisome in previous years. This fact may lead to enlarge surveillance programs with those candidates (e.g. Mycoplasma genitalium, Stenotrophomonas maltophilia or Bordetella pertussis). Other AMR public health threats followed-up in detail, but not covered in this study, can be assessed with this framework; e.g. HIV-AIDS, especially when the first PDR HIV virus has been reported (Puertas et al., 2020). Resilience in healthcare systems is important, especially when running out of options. And, in that way, the new coronavirus disease 2019 (COVID-19) pandemic has jeopardized our health system showing the problems of untreatable infectious diseases bringing to light the remaining strategies to contain them which are difficult and costly involving prevention, contact precaution and isolation of carriers in different settings. Some non-linear dynamics pointed before can also apply to COVID-19 and other infectious diseases such longdistance transmission. In this novel situation, precautionary principles apply and patients may receive antibiotics that can end up being unnecessary. Suspected hospitalized COVID-19 patients are often treated with antibiotic when only in a minority may be appropriate (Antimicrobial resistance in the age of COVID-19., 2020). Effective stewardship and antibiotic limitation during the pandemic is priority as increased and prolonged use of antibiotics can 


\section{The Anthropocene Operating Space for antimicrobial resistance: tipping points in treatability of priority pathogens}

enforce a time-bomb for AMR. Food for thought is that AMR microorganisms can jeopardize the situation in no time especially in healthcare associated untreatable infections.

\section{e. Conclusions}

To conclude, this novel framework assessed 12 out of 20 pathogens in a high compromised situation regarding antimicrobial effectiveness and therapy sustainability: 7 assessed in the surpassed and 5 in the uncertain high risk zones, respectively. The AOS for AMR can be implemented without major efforts worldwide and must be taken as a global risk-assessment of acquired resistance and therapy available at the practical level of species framing threats we are already dealing with, here and now, not in the future. Global coordinated and interdisciplinary action using a common framework for a better communication is the best option that we have in this complex adaptive system. The challenge of AMR needs interdisciplinary frameworks, like this one, as common ground for communication and collaboration between different actors and stakeholders while surveillance and research of infectious diseases must still be milestones. Facing the truth, mortality, morbidity and costs are predictably going to increase as options for treating these priority pathogens are scarce, when available, because we have already surpassed our limits in a concerning number of cases but it is in our hands to minimize the increase of this gradient strengthening efforts from different perspectives.

\section{Conflict of Interest}

The authors declare that the research was conducted in the absence of any commercial or financial relationships that could be construed as a potential conflict of interest.

\section{Authors' Contribution}

PSJ initiated the framework and all authors (TG, CH and PSJ) drafted a schematic model. TG wrote the manuscript including tables and figure. TG and $\mathrm{CH}$ did a narrative review of the literature on AMR. All authors (TG, $\mathrm{CH}$ and PSJ) provided comments and suggestions on the final manuscript.

\section{Funding}

TG was funded through the fifth JPIAMR call by the Swedish Research Council grant number 2017-05981. PSJ was funded through a FORMAS grant number 2016-00451 and through the Erling Person Family Fund. CH was funded through an "Erasmus +" programme to pursue her BSc thesis in Stockholm Resilience Centre, Stockholm University, Stockholm, Sweden.

\section{References:}

Alirol, E., Wi, T. E., Bala, M., Bazzo, M. L., Chen, X. S., Deal, C., et al. (2017). Multidrug-resistant gonorrhea: A research and development roadmap to discover new medicines. PLoS Med. 14. doi:10.1371/journal.pmed.1002366.

AMResilience (https://amr-resilience.gtglab.net/) Available at: https://amr-resilience.gtglab.net/ [Accessed June 11, 2020].

Andersson, D. I., and Hughes, D. (2011). Persistence of antibiotic resistance in bacterial populations. FEMS Microbiol. Rev. 35, 901-911. 


\section{The Anthropocene Operating Space for antimicrobial resistance: tipping points in treatability of priority pathogens}

Andersson, D. I., Nicoloff, H., and Hjort, K. (2019). Mechanisms and clinical relevance of bacterial heteroresistance. Nat. Rev. Microbiol. 17, 479-496. doi:10.1038/s41579-019-0218-1.

Antimicrobial resistance in the age of COVID-19. (2020). Nat. Microbiol. 5, 779-779. doi:10.1038/s41564-020-0739-4.

Arendrup, M. C., and Patterson, T. F. (2017). Multidrug-resistant candida: Epidemiology, molecular mechanisms, and treatment. J. Infect. Dis. 216, S445-S451. doi:10.1093/infdis/jix131.

Ashley, E. A., Recht, J., Chua, A., Dance, D., Dhorda, M., Thomas, N. V, et al. (2018). An inventory of supranational antimicrobial resistance surveillance networks involving low- and middleincome countries since 2000. J. Antimicrob. Chemother. 73, 1737-1749. doi:10.1093/jac/dky026.

Aslam, B., Wang, W., Arshad, M. I., Khurshid, M., Muzammil, S., Rasool, M. H., et al. (2018). Antibiotic resistance: a rundown of a global crisis. Infect. Drug Resist. 11, 1645-1658. doi:10.2147/IDR.S173867.

Avgoulea, K., Pilato, V. Di, Zarkotou, O., Sennati, S., Politi, L., Cannatelli, A., et al. (2018). Characterization of Extensively Drug-Resistant or Pandrug-Resistant Sequence Type 147 and 101 OXA-48-Producing Klebsiella pneumoniae Causing Bloodstream Infections in Patients in an Intensive Care Unit. Antimicrob. Agents Chemother. 62. doi:10.1128/AAC.02457-17.

Bengtsson-Palme, J., Kristiansson, E., and Larsson, D. G. J. (2018). Environmental factors influencing the development and spread of antibiotic resistance. FEMS Microbiol. Rev. 42, 6880. doi:10.1093/femsre/fux053.

Boucher, H. W., Talbot, G. H., Bradley, J. S., Edwards, J. E., Gilbert, D., Rice, L. B., et al. (2009). Bad Bugs, No Drugs: No ESKAPE! An Update from the Infectious Diseases Society of America. Clin. Infect. Dis. 48, 1-12. doi:10.1086/595011.

Boyanova, L., Hadzhiyski, P., Kandilarov, N., Markovska, R., and Mitov, I. (2019). Multidrug resistance in Helicobacter pylori: current state and future directions. Expert Rev. Clin. Pharmacol. 12, 909-915. doi:10.1080/17512433.2019.1654858.

Brauner, A., Fridman, O., Gefen, O., and Balaban, N. Q. (2016). Distinguishing between resistance, tolerance and persistence to antibiotic treatment. Nat. Rev. Microbiol. 14, 320-330. doi:10.1038/nrmicro.2016.34.

Cabrera, R., Fernández-Barat, L., Motos, A., López-Aladid, R., Vázquez, N., Panigada, M., et al. (2020). Molecular characterization of methicillin-resistant Staphylococcus aureus clinical strains from the endotracheal tubes of patients with nosocomial pneumonia. Antimicrob. Resist. Infect. Control 9. doi:10.1186/s13756-020-0679-z.

Cámara, J., Serra, J., Ayats, J., Bastida, T., Carnicer-Pont, D., Andreu, A., et al. (2012). Molecular characterization of two high-level ceftriaxone-resistant Neisseria gonorrhoeae isolates detected in Catalonia, Spain. J. Antimicrob. Chemother. 67, 1858-1860. doi:10.1093/jac/dks 162.

Cantón, R., González-Alba, J. M., and Galán, J. C. (2012). CTX-M enzymes: Origin and diffusion. Front. Microbiol. 3. doi:10.3389/fmicb.2012.00110.

CDC_2019 Biggest Threats and Data | Antibiotic/Antimicrobial Resistance. Available at: https://www.cdc.gov/drugresistance/biggest-threats.html [Accessed November 9, 2019].

Cheng, G., Ning, J., Ahmed, S., Huang, J., Ullah, R., An, B., et al. (2019). Selection and dissemination of antimicrobial resistance in Agri-food production. Antimicrob. Resist. Infect. Control 8, 1-13. doi:10.1186/s13756-019-0623-2. 


\section{The Anthropocene Operating Space for antimicrobial resistance: tipping points in treatability of priority pathogens}

Cillóniz, C., Garcia-Vidal, C., Ceccato, A., and Torres, A. (2018). "Antimicrobial Resistance Among Streptococcus pneumoniae," in Antimicrobial Resistance in the 21st Century (Springer International Publishing), 13-38. doi:10.1007/978-3-319-78538-7_2.

Ciofu, O., and Tolker-Nielsen, T. (2019). Tolerance and resistance of Pseudomonas Aeruginosa biofilms to antimicrobial agents: how P. aeruginosa can escape antibiotics. Front. Microbiol. 10. doi:10.3389/fmicb.2019.00913.

Cruz, J., Graells, T., Walldén, M., and Hjort, K. (2019). Inertial focusing with sub-micron resolution for separation of bacteria. Lab Chip 19, 1257-1266. doi:10.1039/C9LC00080A.

Cuypers, W. L., Jacobs, J., Wong, V., Klemm, E. J., Deborggraeve, S., and van Puyvelde, S. (2018). Fluoroquinolone resistance in Salmonella: Insights by wholegenome sequencing. Microb. Genomics 4. doi:10.1099/mgen.0.000195.

ECDC (2018). Extensively drug-resistant (XDR) Neisseria gonorrhoeae in the United Kingdom and Australia. Heal. Prot. Rep. Adv. Access Rep. 12, 1-11. Available at: https://ecdc.europa.eu/sites/portal/files/documents/RRA-Gonorrhoea\%2C Antimicrobial resistance-United Kingdom\%2C Australia.pdf.

ECDC (2019). Tuberculosis surveillance and monitoring in Europe (2017 data). Available at: https://ecdc.europa.eu/sites/portal/files/documents/tuberculosis-surveillance-monitoring-Europe2019-20_Mar_2019.pdf.

EFSA-ECDC (2020). The European Union Summary Report on Antimicrobial Resistance in zoonotic and indicator bacteria from humans, animals and food in 2017/2018. EFSA J. 18. doi:10.2903/j.efsa.2020.6007.

Ferretti, J. J., Stevens, D. L., and Fischetti, V. a (2016). Streptococcus pyogenes: Basic Biology to Clinical Manifestations. Streptococcus pyogenes Basic Biol. to Clin. Manifestations, 1-15. Available at: https://www.ncbi.nlm.nih.gov/books/NBK333414/ [Accessed May 24, 2020].

Fisher, R. A., Gollan, B., and Helaine, S. (2017). Persistent bacterial infections and persister cells. Nat. Rev. Microbiol. 15, 453-464. doi:10.1038/nrmicro.2017.42.

Forsberg, K., Woodworth, K., Walters, M., Berkow, E. L., Jackson, B., Chiller, T., et al. (2019). Candida auris: The recent emergence of a multidrug-resistant fungal pathogen. Med. Mycol. 57, 1-12. doi:10.1093/mmy/myy054.

Frost, I., Van Boeckel, T. P., Pires, J., Craig, J., and Laxminarayan, R. (2019). Global geographic trends in antimicrobial resistance: the role of international travel. J. Travel Med. doi:10.1093/jtm/taz036.

Göttig, S., Gruber, T. M., Higgins, P. G., Wachsmuth, M., Seifert, H., and Kempf, V. A. J. (2014). Detection of pan drug-resistant Acinetobacter baumannii in Germany. J. Antimicrob. Chemother. 69, 2578-2579. doi:10.1093/jac/dku170.

Gruber, T. M., Göttig, S., Mark, L., Christ, S., Kempf, V. A. J., Wichelhaus, T. A., et al. (2014). Pathogenicity of pan-drug-resistant Serratia marcescens harbouring blaNDM-1. J. Antimicrob. Chemother. 70, 1026-1030. doi:10.1093/jac/dku482.

Gullberg, E., Albrecht, L. M., Karlsson, C., Sandegren, L., and Andersson, D. I. (2014). Selection of a multidrug resistance plasmid by sublethal levels of antibiotics and heavy metals. MBio 5 . doi:10.1128/mBio.01918-14.

Gullberg, E., Cao, S., Berg, O. G., Ilbäck, C., Sandegren, L., Hughes, D., et al. (2011). Selection of Resistant Bacteria at Very Low Antibiotic Concentrations. PLoS Pathog. 7, e1002158. 


\section{The Anthropocene Operating Space for antimicrobial resistance: tipping points in treatability of priority pathogens}

doi:10.1371/journal.ppat.1002158.

Hashemi, M. M., Holden, B. S., Coburn, J., Taylor, M. F., Weber, S., Hilton, B., et al. (2019). Proteomic Analysis of Resistance of Gram-Negative Bacteria to Chlorhexidine and Impacts on Susceptibility to Colistin, Antimicrobial Peptides, and Ceragenins. Front. Microbiol. 10, 210. doi:10.3389/fmicb.2019.00210.

Hendriksen, R. S., Mikoleit, M., Carlson, V. P., Karlsmose, S., Vieira, A. R., Jensen, A. B., et al. (2009). WHO global Salm-Surv external quality assurance system for serotyping of Salmonella isolates from 2000 to 2007. J. Clin. Microbiol. 47, 2729-2736. doi:10.1128/JCM.02437-08.

Henriksson, P. J. G., Rico, A., Troell, M., Klinger, D. H., Buschmann, A. H., Saksida, S., et al. (2018). Unpacking factors influencing antimicrobial use in global aquaculture and their implication for management: a review from a systems perspective. Sustain. Sci. 13, 1105-1120. doi:10.1007/s11625-017-0511-8.

Hernández-García, M., Pérez-Viso, B., Carmen Turrientes, M., Díaz-Agero, C., López-Fresneña, N., Bonten, M., et al. (2018). Characterization of carbapenemase-producing Enterobacteriaceae from colonized patients in a university hospital in Madrid, Spain, during the R-GNOSIS project depicts increased clonal diversity over time with maintenance of high-risk clones. J. Antimicrob. Chemother. 73, 3039-3043. doi:10.1093/jac/dky284.

Hernández-García, M., Pérez-Viso, B., León-Sampedro, R., Navarro-San Francisco, C., LópezFresneña, N., Díaz-Agero, C., et al. (2019). Outbreak of NDM-1+CTX-M-15+DHA-1producing Klebsiella pneumoniae high-risk clone in Spain owing to an undetectable colonised patient from Pakistan. Int. J. Antimicrob. Agents 54, 233-239. doi:10.1016/j.ijantimicag.2019.05.021.

Holmes, A. H., Moore, L. S. P., Steinbakk, M., Regmi, S., Karkey, A., Guerin, P. J., et al. (2015). Understanding the mechanisms and drivers of antimicrobial resistance. Lancet 6736, 1-12. doi:10.1016/S0140-6736(15)00473-0.

Imai, Y., Meyer, K. J., Iinishi, A., Favre-Godal, Q., Green, R., Manuse, S., et al. (2019). A new antibiotic selectively kills Gram-negative pathogens. Nature 576, 459-464. doi:10.1038/s41586019-1791-1.

Jørgensen, P. S., Aktipis, A., Brown, Z., Carrière, Y., Downes, S., Dunn, R. R., et al. (2018). Antibiotic and pesticide susceptibility and the Anthropocene operating space. Nat. Sustain. 1, 632-641. doi:https://doi.org/10.1038/s41893-018-0164-3.

Jørgensen, P. S., Folke, C., Henriksson, P. J. G., Malmros, K., Troell, M., and Zorzet, A. (2020). Coevolutionary Governance of Antibiotic and Pesticide Resistance. Trends Ecol. Evol. 35, 484 494. doi:10.1016/j.tree.2020.01.011.

Karaiskos, I., Lagou, S., Pontikis, K., Rapti, V., and Poulakou, G. (2019). The "Old" and the "New" antibiotics for MDR Gram-negative pathogens: For whom, when, and how. Front. Public Heal. 7. doi:10.3389/fpubh.2019.00151.

Khosravi, A. D., and Mohammadian, A. (2016). Efflux MexAB-Mediated Resistance in Multidrug and Pan-Drug Resistant Strains of Pseudomonas aeruginosa Isolated From Patients With Burn and Wound Infections. Jundishapur J. Nat. Pharm. Prod. 11. doi:10.17795/jjnpp-25352.

Kim, J., Hwang, B. K., Choi, H., Wang, Y., Choi, S. H., Ryu, S., et al. (2019). Characterization of mcr-1-Harboring Plasmids from Pan Drug-Resistant Escherichia coli Strains Isolated from Retail Raw Chicken in South Korea. Microorganisms 7, 344. doi:10.3390/microorganisms7090344. 


\section{The Anthropocene Operating Space for antimicrobial resistance: tipping points in treatability of priority pathogens}

Klein, E. Y., Van Boeckel, T. P., Martinez, E. M., Pant, S., Gandra, S., Levin, S. A., et al. (2018). Global increase and geographic convergence in antibiotic consumption between 2000 and 2015. Proc. Natl. Acad. Sci. U. S. A., 201717295. doi:10.1073/pnas.1717295115.

Kousouli, E., Zarkotou, O., Polimeri, K., Themeli-Digalaki, K., and Pournaras, S. (2019). Impact of bloodstream infections caused by carbapenem-resistant Gram-negative pathogens on ICU costs, mortality and length of stay. Infect. Prev. Pract. 1, 100020. doi:10.1016/j.infpip.2019.100020.

Kraemer, S. A., Ramachandran, A., and Perron, G. G. (2019). Antibiotic Pollution in the Environment: From Microbial Ecology to Public Policy. Microorganisms 7, 180. doi:10.3390/microorganisms7060180.

Kristiansson, E., Fick, J., Janzon, A., Grabic, R., Rutgersson, C., Weijdegård, B., et al. (2011). Pyrosequencing of Antibiotic-Contaminated River Sediments Reveals High Levels of Resistance and Gene Transfer Elements. PLoS One 6, e17038. doi:10.1371/journal.pone.0017038.

Laxminarayan, R., Matsoso, P., Pant, S., Brower, C., Røttingen, J.-A., Klugman, K., et al. (2016). Access to effective antimicrobials: a worldwide challenge. Lancet 387, 168-175.

Levin-Reisman, I., Brauner, A., Ronin, I., and Balaban, N. Q. (2019). Epistasis between antibiotic tolerance, persistence, and resistance mutations. Proc. Natl. Acad. Sci. U. S. A. 116, 1473414739. doi:10.1073/pnas.1906169116.

Liu, Y. Y., Wang, Y., Walsh, T. R., Yi, L. X., Zhang, R., Spencer, J., et al. (2016). Emergence of plasmid-mediated colistin resistance mechanism MCR-1 in animals and human beings in China: A microbiological and molecular biological study. Lancet Infect. Dis. 16, 161-168. doi:10.1016/S1473-3099(15)00424-7.

Lockhart, S. R., Etienne, K. A., Vallabhaneni, S., Farooqi, J., Chowdhary, A., Govender, N. P., et al. (2017). Simultaneous emergence of multidrug-resistant candida auris on 3 continents confirmed by whole-genome sequencing and epidemiological analyses. Clin. Infect. Dis. 64, 134-140. doi:10.1093/cid/ciw691.

Magiorakos, A. P., Srinivasan, A., Carey, R. B., Carmeli, Y., Falagas, M. E., Giske, C. G., et al. (2012). Multidrug-resistant, extensively drug-resistant and pandrug-resistant bacteria: An international expert proposal for interim standard definitions for acquired resistance. Clin. Microbiol. Infect. 18, 268-281. doi:10.1111/j.1469-0691.2011.03570.x.

Martinez-, L., and Simonsen, G. S. (2017). EUCAST_detection_of_resistance_mechanisms_170711. $1-43$.

Martínez, J. L. (2012). Bottlenecks in the Transferability of Antibiotic Resistance from Natural Ecosystems to Human Bacterial Pathogens. Front. Microbiol. 2, 265. doi:10.3389/fmicb.2011.00265.

Martínez, J. L., and Baquero, F. (2014). Emergence and spread of antibiotic resistance: Setting a parameter space. Ups. J. Med. Sci. 119, 68-77. doi:10.3109/03009734.2014.901444.

Mathers, A. J., Peirano, G., and Pitout, J. D. D. (2015). The role of epidemic resistance plasmids and international high- risk clones in the spread of multidrug-resistant Enterobacteriaceae. Clin. Microbiol. Rev. 28, 565-591. doi:10.1128/CMR.00116-14.

Monroe, D. (2007). Looking for Chinks in the Armor of Bacterial Biofilms. PLoS Biol. 5, e307. doi:10.1371/journal.pbio.0050307.

Moraleda, C., Benmessaoud, R., Esteban, J., López, Y., Alami, H., Barkat, A., et al. (2018). Prevalence, antimicrobial resistance and serotype distribution of group B streptococcus isolated 


\section{The Anthropocene Operating Space for antimicrobial resistance: tipping points in treatability of priority pathogens}

among pregnant women and newborns in Rabat, Morocco. J. Med. Microbiol. 67, 652-661. doi:10.1099/jmm.0.000720.

Mustapha, M. M., Li, B., Pacey, M. P., Mettus, R. T., McElheny, C. L., Marshall, C. W., et al. (2018) Phylogenomics of colistin-susceptible and resistant XDR Acinetobacter baumannii. $J$. Antimicrob. Chemother. 73, 2952-2959. doi:10.1093/jac/dky290.

Nicoloff, H., Hjort, K., Levin, B. R., and Andersson, D. I. (2019). The high prevalence of antibiotic heteroresistance in pathogenic bacteria is mainly caused by gene amplification. Nat. Microbiol. 4, 504-514. doi:10.1038/s41564-018-0342-0.

Nowak, J., Zander, E., Stefanik, D., Higgins, P. G., Roca, I., Vila, J., et al. (2017). High incidence of pandrug-resistant Acinetobacter baumannii isolates collected from patients with ventilatorassociated pneumonia in Greece, Italy and Spain as part of the MagicBullet clinical trial. $J$. Antimicrob. Chemother. 72, 3277-3282. doi:10.1093/jac/dkx322.

Ostrowsky, B., Greenko, J., Adams, E., Quinn, M., O’Brien, B., Chaturvedi, V., et al. (2020). Candida auris Isolates Resistant to Three Classes of Antifungal Medications - New York, 2019. MMWR. Morb. Mortal. Wkly. Rep. 69, 6-9. doi:10.15585/mmwr.mm6901a2.

Parry, C. M., and Threlfall, E. (2008). Antimicrobial resistance in typhoidal and nontyphoidal salmonellae. Curr. Opin. Infect. Dis. 21, 531-538. doi:10.1097/QCO.0b013e32830f453a.

Peng, Z., Jin, D., Kim, H. B., Stratton, C. W., Wu, B., Tang, Y. W., et al. (2017). Update on antimicrobial resistance in Clostridium difficile: Resistance mechanisms and antimicrobial susceptibility testing. J. Clin. Microbiol. 55, 1998-2008. doi:10.1128/JCM.02250-16.

Perry, J. A., and Wright, G. D. (2013). The antibiotic resistance "mobilome": searching for the link between environment and clinic. Front. Microbiol. 4, 138. doi:10.3389/fmicb.2013.00138.

Puertas, M. C., Ploumidis, G., Ploumidis, M., Fumero, E., Clotet, B., Walworth, C. M., et al. (2020). Pan-resistant HIV-1 emergence in the era of integrase strand-transfer inhibitors: a case report. The Lancet Microbe 0. doi:10.1016/s2666-5247(20)30006-9.

Puzari, M., Sharma, M., and Chetia, P. (2018). Emergence of antibiotic resistant Shigella species: A matter of concern. J. Infect. Public Health 11, 451-454. doi:10.1016/j.jiph.2017.09.025.

Rice, L. B. (2008). Federal Funding for the Study of Antimicrobial Resistance in Nosocomial Pathogens: No ESKAPE. J. Infect. Dis. 197, 1079-1081. doi:10.1086/533452.

Richter, S. S., Heilmann, K. P., Dohrn, C. L., Riahi, F., Beekmann, S. E., and Doern, G. V. (2009). Changing Epidemiology of Antimicrobial-Resistant Streptococcus pneumoniae in the United States, 2004-2005 . Clin. Infect. Dis. 48, e23-e33. doi:10.1086/595857.

Rolain, J. M., Diene, S. M., Kempf, M., Gimenez, G., Robert, C., and Raoult, D. (2013). Real-time sequencing to decipher the molecular mechanism of resistance of a clinical pan-drug-resistant Acinetobacter baumannii isolate from Marseille, France. Antimicrob. Agents Chemother. 57, 592-596. doi:10.1128/AAC.01314-12.

Said, H. S., and Abdelmegeed, E. S. (2019). Emergence of multidrug resistance and extensive drug resistance among enterococcal clinical isolates in Egypt. Infect. Drug Resist. 12, 1113-1125. doi:10.2147/IDR.S189341.

Shokri, D., Khorasgani, M. R., Zaghian, S., Fatemi, S. M., Mohkam, M., Ghasemi, Y., et al. (2016). Determination of acquired resistance profiles of pseudomonas aeruginosa isolates and characterization of an effective bacteriocin-like inhibitory substance (BLIS) against these isolates. Jundishapur J. Microbiol. 9. doi:10.5812/jjm.32795. 


\section{The Anthropocene Operating Space for antimicrobial resistance: tipping points in treatability of priority pathogens}

Skov, R. L., and Monnet, D. L. (2016). Plasmid-mediated colistin resistance (mcr-1 gene): Three months later, the story unfolds. Eurosurveillance 21, 1-6. doi:10.2807/15607917.ES.2016.21.9.30155.

Sproston, E. L., Wimalarathna, H. M. L., and Sheppard, S. K. (2018). Trends in fluoroquinolone resistance in campylobacter. Microb. Genomics 4, e000198. doi:10.1099/mgen.0.000198.

Steffen, W., Richardson, K., Rockstrom, J., Cornell, S. E., Fetzer, I., Bennett, E. M., et al. (2015). Planetary boundaries: Guiding human development on a changing planet. Science (80-. ). 347, 1259855-1259855. doi:10.1126/science.1259855.

Stokes, H. W., and Gillings, M. R. (2011). Gene flow, mobile genetic elements and the recruitment of antibiotic resistance genes into Gram-negative pathogens. FEMS Microbiol. Rev. 35, 790-819. doi:10.1111/j.1574-6976.2011.00273.x.

Strogatz, S. H. (2007). Nonlinear Dynamics And Chaos. Sarat Book House Available at: https://books.google.se/books?id=PHmED2xxrE8C.

Su, P. Y., Huang, A. H., Lai, C. H., Lin, H. F., Lin, T. M., and Ho, C. H. (2020). Extensively drugresistant Haemophilus influenzae - emergence, epidemiology, risk factors, and regimen. BMC Microbiol. 20, 102. doi:10.1186/s12866-020-01785-9.

Tapsall, J. W., Ndowa, F., Lewis, D. A., and Unemo, M. (2009). Meeting the public health challenge of multidrug- and extensively drug-resistant Neisseria gonorrhoeae. Expert Rev. Anti. Infect. Ther. 7, 821-34. doi:10.1586/eri.09.63.

Trebosc, V., Gartenmann, S., Tötzl, M., Lucchini, V., Schellhorn, B., Pieren, M., et al. (2019). Dissecting Colistin Resistance Mechanisms in Extensively Drug-Resistant Acinetobacter baumannii Clinical Isolates. MBio 10. doi:10.1128/mBio.01083-19.

Tsala, M., Vourli, S., Georgiou, P.-C., Pournaras, S., Daikos, G. R. L., Mouton, J. W., et al. (2019). Triple combination of meropenem, colistin and tigecycline was bactericidal in a dynamic model despite mere additive interactions in chequerboard assays against carbapenemase-producing Klebsiella pneumoniae isolates. J. Antimicrob. Chemother. 74, 387-394. doi:10.1093/jac/dky422.

Ur Rahman, S., Ali, T., Ali, I., Khan, N. A., Han, B., and Gao, J. (2018). The Growing Genetic and Functional Diversity of Extended Spectrum Beta-Lactamases. Biomed Res. Int. 2018. doi:10.1155/2018/9519718.

US CDC (2019). Antibiotic resistance threats in the United States. Centers Dis. Control Prev., 1-150.

Van Boeckel, T. P., Emma, E., Chen, D., Gilbert, M., Robinson, T. P., Grenfell, B. T., et al. (2017). Reducing antimicrobial use in food animals. Science 357, 1350-1352. doi:10.1126/science.aao1495.

Van Boeckel, T. P., Pires, J., Silvester, R., Zhao, C., Song, J., Criscuolo, N. G., et al. (2019). Global trends in antimicrobial resistance in animals in low- and middle-income countries. Science (80-. ). 365. doi:10.1126/science.aaw 1944 .

van Duin, D., and Doi, Y. (2017). The global epidemiology of carbapenemase-producing Enterobacteriaceae. Virulence 8, 460-469. doi:10.1080/21505594.2016.1222343.

Van Hoek, A. H. A. M., Mevius, D., Guerra, B., Mullany, P., Roberts, A. P., and Aarts, H. J. M. (2011). Acquired antibiotic resistance genes: An overview. Front. Microbiol. 2. doi:10.3389/fmicb.2011.00203.

Vila, J., Moreno-Morales, J., and Ballesté-Delpierre, C. (2019). Current landscape in the discovery of 


\section{The Anthropocene Operating Space for antimicrobial resistance: tipping points in treatability of priority pathogens}

novel antibacterial agents. Clin. Microbiol. Infect. 0. doi:10.1016/j.cmi.2019.09.015.

Wang, C., Feng, Y., Liu, L., Wei, L., Kang, M., and Zong, Z. (2020). Identification of novel mobile colistin resistance gene mcr-10. Emerg. Microbes Infect. 9, 508-516. doi:10.1080/22221751.2020.1732231.

Wernli, D., Jørgensen, P. S., Harbarth, S., Carroll, S. P., Laxminarayan, R., Levrat, N., et al. (2017). Antimicrobial resistance: The complex challenge of measurement to inform policy and the public. 14, 1-9. doi:10.1371/journal.pmed.1002378.

Whelan, M. V. X., Ardill, L., Koide, K., Nakajima, C., Suzuki, Y., Simpson, J. C., et al. (2019). Acquisition of fluoroquinolone resistance leads to increased biofilm formation and pathogenicity in Campylobacter jejuni. Sci. Rep. 9, 1-13. doi:10.1038/s41598-019-54620-1.

WHO_2017 World Health Organization-List of bacteria for which new antibiotics are urgently needed. $27 \mathrm{Febr}$. 2017. Available at: https://www.who.int/news-room/detail/27-02-2017-whopublishes-list-of-bacteria-for-which-new-antibiotics-are-urgently-needed [Accessed November 13, 2019].

WHO (2017). Global Antimicrobial Resistance Surveillance System (GLASS) Report. Geneva, World Health Organization. doi:ISBN 978-92-4-151344-9.

Wistrand-Yuen, E., Knopp, M., Hjort, K., Koskiniemi, S., Berg, O. G., and Andersson, D. I. (2018). Evolution of high-level resistance during low-level antibiotic exposure. Nat. Commun. 9. doi:10.1038/s41467-018-04059-1.

Woerther, P. L., Burdet, C., Chachaty, E., and Andremont, A. (2013). Trends in human fecal carriage of extended-spectrum $\beta$-lactamases in the community: Toward the globalization of CTX-M. Clin. Microbiol. Rev. 26, 744-758. doi:10.1128/CMR.00023-13. 